FACULDADE DE PSICOLOGIA E DE CIÊNCIAS DA EDUCAÇÃO DA UNIVERSIDADE DE COIMBRA

\title{
MANUAL DE INTRODUÇÃO AO MODELO DE AVALIAÇÃO E DE INTERVENÇÃO FAMILIAR INTEGRADA PARA O ENCAMINHADOR
}

Ana Melo \& Madalena Alarcão 


\section{ÍNDICE}

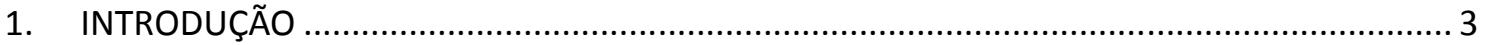

2. O QUE É O MODELO DE AVALIAÇÃO E DE INTERVENÇÃO FAMILIAR INTEGRADA? ............... 3

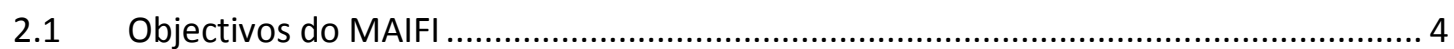

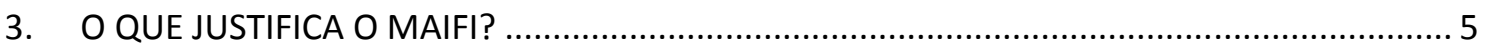

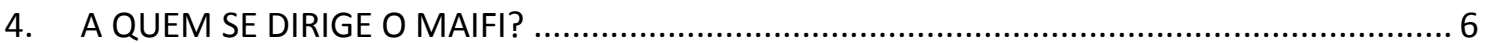

5. ETAPAS DO MAIFI E DURAÇÃO DA IMPLEMENTAÇÃO ......................................................... 7

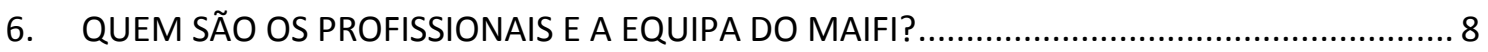

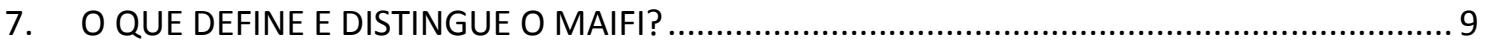

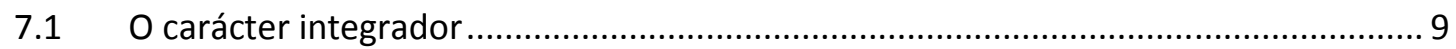

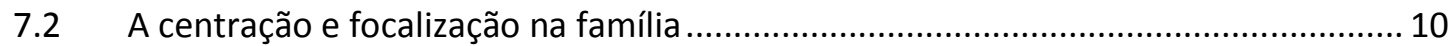

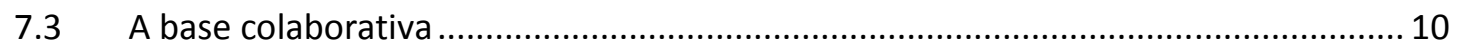

7.4 A orientação para as forças e processos de resiliência ................................................. 11

7.5 O foco nas soluções e a orientação narrativa ............................................................. 12

8. COMO SE ARTICULA O MAIFI COM OUTROS SERVIÇOS E RESPOSTAS? ................................ 12

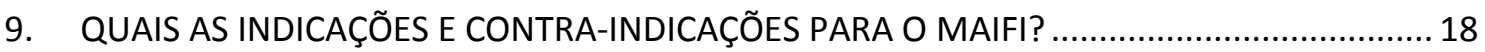

10. QUE CONDIÇÕES DEVEM ESTAR ASSEGURADAS AQUANDO DO ENCAMINHAMENTO

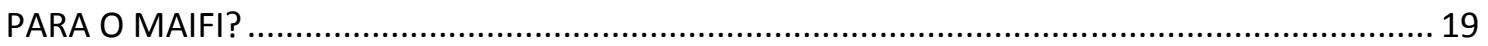

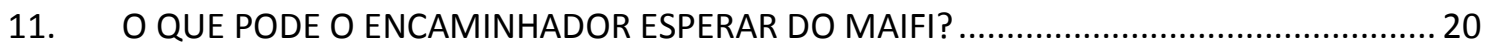

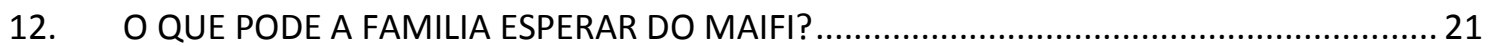

13. QUAIS OS ASPECTOS PARTICULARES DA AVALIAÇÃO NO MAIFI? ...................................... 22

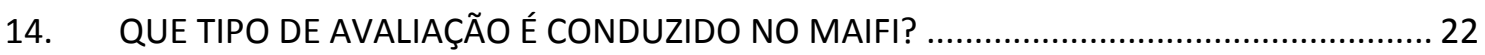

15. O QUE CARACTERIZA A FASE DE SUPORTE PARA A MUDANÇA NO MAIFI?..................... 25

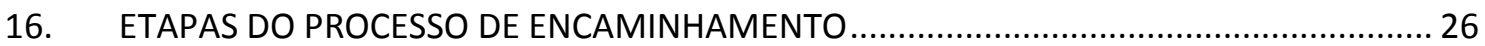
ANEXO 1 Erro! Marcador não definido. GUIÃO DE PREPARAÇÃO PARA O ENCAMINHAMENTO PARA O MAIFI ...........Erro! Marcador não definido.

ANEXO 2 Erro! Marcador não definido.

O PREENCHIMENTO DA FICHA DE ENCAMINHAMENTO PASSO A PASSO .......Erro! Marcador não definido.

ANEXO 3 Erro! Marcador não definido.

EXEMPLO DE MODELO DE RELATÓRIO DE AVALIAÇÃO Erro! Marcador não definido. ANEXO 4 Erro! Marcador não definido. EXEMPLO DE CASO Erro! Marcador não definido. 


\section{INTRODUÇÃO}

Este manual tem um objectivo duplo. Por um lado, para aqueles que desconhecem o Modelo de Avaliação e de Intervenção Familiar Integrada visa dar a conhecer, de forma sumária o modelo e as suas especificidades. O sucesso da implementação do MAIFI está, em larga medida associado ao sucesso da complementaridade da sua acção com a de outros serviços de modo a optimizar a viabilidade e utilidade da avaliação e os esforços de apoio à família. Este manual visa dar a conhecer o MAIFI ao profissional e comunidades locais, particularmente aqueles que têm uma acção mais centrada nas famílias e que actuam em diferentes níveis do sistema de promoção e protecção.

Para aquele que têm já algum conhecimento do MAIFI ou que frequentaram alguma acção de formação de introdução ao mesmo e ao processo de encaminhamento, este manual visa sistematizar a informação e oferecer orientações que apoiem o processo de encaminhamento de modo a optimizar-se o trabalho desenvolvido posteriormente. O leitor que já tem conhecimento considerável do modelo poderá consultar directamente o Guião do Encaminhamento para o MAIFI- onde encontrará um esquema de apoio ao processo de tomada de decisão associado ao encaminhamento para o MAIFI e o guião detalhado de apoio ao preenchimento da ficha de encaminhamento.

\section{O QUE É O MODELO DE AVALIAÇÃO E DE INTERVENÇÃO FAMILIAR INTEGRADA?}

O Modelo de Avaliação e de Intervenção Familiar Integrada (MAIFI) é uma resposta de avaliação e intervenção centrada na família, multissistémica, ou seja, que se foca não só no funcionamento intrafamiliar mas, também, na sua ligação com o meio e com os sistemas em que se insere, e com os quais estabelece relações que, num ou noutro momento, podem ser mais ou menos facilitadoras do desenvolvimento e adaptação da família e dos seus elementos, particularmente das crianças e dos jovens.

É um modelo que integra, num todo coerente e articulado, e a partir de um fundamento sistémico e de uma postura de base colaborativa, diferentes tipos de abordagens (terapêutica, social, educativa, comunitária) e contributos de diferentes modelos de avaliação e intervenção 
familiar e parental. É, ainda, um modelo de orientação focado nas forças e em processos de resiliência, com influências das abordagens narrativas e centradas nas soluções.

Trata-se de uma abordagem em que o trabalho com a família decorre privilegiadamente em contexto domiciliário e comunitário, procurando-se tirar o máximo partido das vantagens oferecidas por estes contextos.

Constituem princípios orientadores do MAIFI:

a) Uma orientação ecológica e (multi)sistémica;

b) Um enfoque na família;

c) Um enfoque no reforço de competências relacionais intra e intersistémicas;

d) Uma orientação para a procura, activação e potenciação das forças, competências e processos de resiliência;

e) A adopção de uma postura optimista, colaborativa, reflexiva, respeitadora e promotora de autonomia e do empowerment da família em relação com a sua ecologia;

f) Um enfoque na protecção e promoção da segurança e do bem-estar da família em geral e em particular da criança e do jovem, respeitando o superior interesse destes últimos.

\subsection{Objectivos do MAIFI}

Constituem objectivos gerais do MAIFI os seguintes:

- Promover o fortalecimento das famílias;

- Proteger e potenciar o bem-estar físico, psicológico e social dos elementos das famílias.

São objectivos específicos:

- Avaliar as dinâmicas de risco e protecção das famílias e as possibilidades de mudança;

- Aumentar a segurança e bem-estar integrado (físico, psicológico, social) dos elementos das famílias, particularmente das crianças.

- Aumentar a percepção da família de viver de acordo com as visões preferidas de si mesma e as suas direç̧ões preferidas de vida;

- Aumentar a capacidade da família de exercer o seu direito à liberdade;

- Aumentar processos de resiliência familiar (a nível da dimensão das crenças familiares, processos organizacionais e capacidade de comunicação e resolução de problemas) e individual; 
- Aumentar a qualidade das condições sociais de vida das famílias e/ou a sua capacidade de as melhorarem;

- Aumentar competências parentais (ao nível dos cuidados básicos, segurança afectiva, orientação e estabelecimento de limites, segurança e estimulação) facilitadoras de um desenvolvimento positivo das crianças e jovens;

- Diminuir os problemas e mau estar percebidos pelas famílias.

\section{O QUE JUSTIFICA O MAIFI?}

Quer ao nível da investigação, quer na prática, há um conjunto de necessidades que justificam a existência de uma abordagem diferenciada com as características do MAIFI. Este modelo foi desenhado para dar resposta, por um lado, às necessidades complexas das famílias que experimentam múltiplos desafios e, por outro, às necessidades dos profissionais que trabalham em diferentes níveis do sistema de promoção e protecção.

As famílias multidesafiadas podem beneficiar de um tipo de abordagem que minimize os riscos da múltipla assistência (Colapinto, 1995; Reder, 1986) e que proporcione respostas integradoras. A intervenção com estas famílias deve ter em consideração o impacto das suas condições sociais de vida no funcionamento e relações familiares e saúde mental dos seus elementos (Frankel \& Frankel, 2006; Rojano, 2004). A complexidade da vida destas famílias e a ineficácia e problemas apontadas às respostas tradicionais apelam ao desenvolvimento de respostas e posturas alternativas (McNeil \& Herschell, 1998; Sousa \& Eusébio, 2005; KrumerNevo, Slonim-Nevo, \& Hirshenzon-Segev, 2006). Por outro lado, as famílias multidesafiadas podem beneficiar de um trabalho focado na família que permita activar processos chave para a adaptação da mesma a contextos de adversidade e de um centrado nas suas forças e recursos para melhor fazer face às dificuldades e vulnerabilidades emergentes (Madsen, 2007; Saleebey, 2000; Sousa, Ribeiro, \& Rodrigues, 2006). O MAIFI foi construído para ir ao encontro destas preocupações.

Nas situações de maltrato a investigação tem apontado não só várias vulnerabilidades nas metodologias de avaliação como no processo de tomada de decisão e análise da informação produzida, bem como nos padrões de comunicação entre profissionais, entre outros aspectos (Farmer, 1999; MacDonald, 2001; Munro, 2008). Em Portugal, escasseiam modelos e instrumentos de avaliação estruturados e integradores para situações de perigo e risco. Acontece, ainda, que avaliação e intervenção estão, frequentemente separadas e são geridas a partir do referencial do especialista e com enfoque nos problemas, desperdiçandose, desta forma, oportunidades de, desde o inicio do contacto com os profissionais, facilitar-se 
o envolvimento da família num processo de mudança, e apoiar-se este processo ainda durante a fase de avaliação contribuindo-se, assim, para aumentar a probabilidade de sucesso. A avaliação no MAIFI está organizada em função da literatura e combina diferentes perspectivas numa grelha integradora orientadora para a avaliação em situações de risco e perigo, particularmente maus tratos e negligência. Informa e coloca ao dispor dos profissionais instrumentos e metodologias de recolha de informação, bem como orientações para o processo de síntese e análise da informação.

São conhecidas as dificuldades no estabelecimento de relações cooperativas de trabalho em contexto de coaç̧ão. Estas dificuldades podem ser tanto maiores quanto a relação entre profissional família é marcada pela verticalidade, com destaque para a posição de poder do profissional, e focada nos problemas. As abordagens colaborativas em que o MAIFI se inspira, pelo carácter mais partilhado da distribuição da responsabilidade e poder, pela abertura e respeito aos saberes e perspectivas da família e pelo seu enfoque nas soluções e nas forças, podem ser mais bem sucedidas no estabelecimento de uma relação de trabalho útil e eficaz entre profissionais e família, com melhores resultados (Berg \& Kelly, 2000; Turnell \& Edwards, 1999; Madsen, 2007, 2009).

O MAIFI procura, desta forma, dar resposta a necessidades identificadas no panorama nacional e na literatura internacional. Foi construído de modo a apoiar os profissionais que trabalham no sistema de protecção e protecção e que, frequentemente, sentem dificuldades na condução dos processos de avaliação e nos processos de apoio à família. Por outro lado, procura oferecer uma resposta que melhor contribua para que os múltiplos desafios experimentados por algumas famílias se convertam em forças ou resultem em adaptação positiva em vez de vulnerabilidades ou problemas.

\section{A QUEM SE DIRIGE O MAIFI?}

Dadas as suas características, particularmente o carácter integrador, o MAIFI é particularmente indicado para situações em que é necessário uma avaliação e intervenção de alguma complexidade que articule diferentes variáveis e dimensões do funcionamento familiar, dos indivíduos da família mas também dos seus contextos sociais e ambientais de vida e da relação com outros sistemas.

A população-alvo privilegiada no MAIFI é constituída por famílias multidesafiadas com crianças e jovens em situação de risco psicossocial e/ou famílias com crianças e jovens em situação de perigo, particularmente maltratadas e negligenciadas. 
As famílias multidesafiadas podem ser definidas como aquelas que: a) viveram ou vivem em condições de vida adversas (como viver em circunstâncias de pobreza, as situações mais indicadas para o MAIFI, ou experienciar situações de exclusão social, opressão ou violência comunitária), experienciando uma exposição prolongada, embora não necessariamente aguda a ambientes stressantes ou, por outro lado, experienciaram circunstâncias de vida duras, durante períodos de tempo curtos mas com uma exposição a stress muito intenso; $\mathrm{E}$ b) que lidaram ou lidam com múltiplos desafios ou múltiplos stressores em simultâneo, frequentemente em paralelo com crises normativas (Melo \& Alarcão, 2011).

Por outro lado, o MAIFI visa apoiar os diferentes intervenientes no sistema de promoção e protecção na medida em que os processos de avaliação e de suporte para a mudança, através da informação produzida, podem facilitar o processo de tomada de decisão.

\section{ETAPAS DO MAIFI E DURAÇÃO DA IMPLEMENTAÇÃO}

O MAIFI organiza-se em 5 etapas: a) encaminhamento; b) acolhimento; c) avaliação; d) suporte para a mudança; e) follow-up e finalização. A cada etapa corresponde um subconjunto específico de objectivos, de procedimentos e tarefas. A duração média de um caso que tenha seguimento na fase de suporte para a mudança, até à entrada na fase de follow-up, é de cerca de 12 meses, podendo, contando com esse período, perfazer os 18 a 24 meses, conforme as características específicas dos casos.

Passa-se a enumerar, brevemente, para cada etapa, os objectivos e tempo estimado de duração.

A fase de encaminhamento tende a ter uma duração média de cerca de uma semana, período para a equipa analisar os critérios de inclusão do caso no MAIFI, o pedido efectuado e a sua capacidade presente de resposta de modo a elaborar uma resposta ao encaminhamento sobre a aceitação do mesmo. A fase de encaminhamento é de crucial importância, podendo dela depender o sucesso das etapas seguintes. Os principais objectivos consistem em: a) recolher informação sobre a situação da família; b) definir os contornos da fase de avaliação; c) clarificar os papéis, responsabilidades e modos de articulação entre a equipa do MAIFI e outros profissionais; d) avançar com hipóteses de trabalho e definir o contexto inicial e os elementos da equipa que vão estar envolvidos. Nesta fase podem, assim, ser envolvidos o encaminhador, a equipa do MAIFI e, eventualmente, outros profissionais a trabalhar actualmente com a família.

A fase de acolhimento constitui, por norma, o momento de primeiro contacto com a família. Os principais objectivos incluem: a) criar uma relação de colaboração com a família; b) 
negociar e definir os contornos do pedido e da relação entre a família, o CAFAP e outros profissionais/organizações; c) definir estratégias de trabalho e negociar objectivos e procedimentos para o período de avaliação. Esta etapa tende a decorrer entre uma e três sessões.

A fase de avaliação, cujas características detalharemos adiante, tem uma duração que varia entre um e três meses, em média. Constituem objectivos específicos: a) avaliar as principais forças e vulnerabilidades da família relativamente ao risco de maus tratos futuros e às possibilidades de ajustamento e desenvolvimento positivo da criança e da família; b) construir hipóteses em torno dos factores que contribuíram para a emergência e manutenção dos problemas e dos factores constrangedores ou facilitadores da construção de condições de segurança e do desenvolvimento das visões, direcções e intenções preferidas de vida da família; c) aumentar a disponibilidade da família para a mudança; d) avaliar o potencial de mudança da família avançando com prognósticos; e) definir possibilidades e estratégias de suporte à mudança e elaborar um relatório de avaliação.

A fase de suporte para a mudança tende ter a duração de cerca de um ano, embora com uma intensidade que varia no decorrer do mesmo, tendencialmente mais intensiva nos primeiros três meses. São objectivos específicos desta etapa, os seguintes: a) aumentar a segurança e bem-estar dos elementos da família, em particular da criança; b) aumentar a percepção da família de viver de acordo com as visões preferidas de si e suas direcções preferidas de vida; c) aumentar a capacidade da família de exercer o seu direito à liberdade; d) aumentar processos de resiliência familiar (a nível da dimensão das crenças familiares, processos organizacionais e capacidade de comunicação e resolução de problemas) e individual e a capacidade associada da família de lidar com os múltiplos desafios com que se confronta; e) aumentar a qualidade das condições sociais de vida das famílias e/ou a sua capacidade de as melhorarem; f) aumentar competências parentais (ao nível dos cuidados básicos, segurança afectiva, orientação e estabelecimento de limites, segurança e estimulação) facilitadoras de um desenvolvimento positivo das crianças e jovens; g) diminuir os problemas e mau estar percebidos pelas famílias; h) aumentar o bem-estar integrado (físico, psicológico, social) dos elementos das famílias.

\section{QUEM SÃO OS PROFISSIONAIS E A EQUIPA DO MAIFI?}

O MAIFI foi desenhado especificamente para ser implementado em Centros de Apoio Familiar e de Aconselhamento Parental e, por isso, é das equipas destes serviços, que, na maioria das situações, saem os seus profissionais. 
A equipa de profissionais do MAIFI é, por norma, composta por um mínimo de 3 profissionais, habitualmente, um psicólogo, um assistente social e um educador social. Para cada caso são destacados dois profissionais embora um deles possa assumir-se como gestor de caso primário. O terceiro elemento normalmente colabora no processo de forma indirecta, podendo, contudo, quando justificado, ter contacto directo com a família. Por norma, todos os elementos da equipa tiveram formação específica para implementação do $\mathrm{MAIFI}^{1}$ e a equipa usufrui de supervisão.

A equipa de profissionais do MAIFI é uma equipa inter e transdisciplinar que desenvolve um trabalho conjunto, de forma integrada, com base numa grelha de leitura comum das realidades, funcionamento e processos de adaptação das famílias.

Sendo o MAIFI uma abordagem colaborativa centrada na família e na comunidade, naturalmente poderão ser envolvidos outros elementos significativos da rede da família ou da comunidade como parceiros na equipa de apoio à família, quer durante a fase de avaliação quer na fase de suporte para a mudança.

\section{O QUE DEFINE E DISTINGUE O MAIFI?}

Há algumas características particularmente importantes no MAIFI, que definem a sua identidade e que o distinguem de outras respostas e que passamos, sumariamente, a descrever, juntamente com as suas implicações.

\subsection{0 carácter integrador}

O MAIFI constitui-se como um modelo inter e transdisciplinar. A integração de diferentes perspectivas, olhares e abordagens dá-se tendo por base um olhar sistémico e uma postura colaborativa. O MAIFI surge como modelo em que serviços terapêuticos, sociais, educativos e comunitários, se aliam e se cruzam, frequentemente com implicações forenses, nos casos de proteç̧ão, de modo a optimizar o processo de fortalecimento, desenvolvimento positivo e mudança da família e a garantir que estes decorrem de uma forma coerente, respeitando a integridade da família e da sua vida como um todo.

\footnotetext{
1 Nalguns casos, e a título excepcional, apenas alguns dos elementos da equipa receberam formação, sendo que nessas situações deverá ser sempre destacado um destes elementos para a equipa gestora do caso. Contudo, todos deverão usufruir de supervisão. O processo de formação para a implementação do MAIFI é organizado em duas etapas. No decorrer da primeira é combinado um registo de formação individual autónoma, com formação em grupo e momento de formação individual supervisionada no decurso de 9 meses correspondentes a 9 módulos de formação. Após este período os profissionais experimentam um período de prática supervisionada regular, com a duração de, aproximadamente, um ano, período após o qual participam em momentos de supervisão.
} 
Para além de se basear numa proposta teórica integradora sobre os processos de adaptação das famílias multidesafiadas, o carácter integrador do MAIFI reflecte-se, também, na prática, na combinação de metodologias de avaliação e de estratégias derivadas de diferentes modelos que podem ser incorporadas na fase de suporte para a mudança.

\subsection{A centração e focalização na família}

É na família e nos processos de funcionamento familiar que o olhar e o trabalho dos profissionais do MAIFI se centra e é a partir dela que os profissionais procuram compreender a sua realidade, alargando o olhar para incluir, nesta compreensão, a relação com outros sistemas e o papel das circunstâncias sociais e ambientais de vida da família bem como o impacto para os elementos da família e cumprimento das funções familiares no que a estes diz respeito, particularmente às crianças. O trabalho do MAIFI procura respeitar o funcionamento autónomo da família, e as suas regras de funcionamento, entendendo-a como melhor especialista de si mesma e considerando que só a família dispõe dos mecanismos para se adaptar ao seu meio e circunstâncias de vida, podendo necessitar de apoio para os activar, mobilizar ou ampliar.

Não obstante a centração na família o MAIFI privilegia a segurança e o bem-estar da criança, pelo que procura definir com a família indicadores claros a este respeito. Contudo, considera ser mais fácil garantir a segurança e o bem-estar da criança quando estes são compatíveis com a forma como a família prefere ver-se, os seus valores, propósitos, ideais e direç̧ões preferidas de vida e quando é apoiada para os realizar. Por isso dois dos três resultados privilegiados no MAIFI incluem, por um lado, a garantia e promoção do bem-estar e protecção da criança e, por outro, a realização das visões (a forma como a família prefere verse e perceber a sua vida) e direcções preferidas de vida da família (os seus valores, propósitos, sonhos, projectos, ideias, aspirações). Enquanto o primeiro dos resultados oferece a direcção de mudanças consideradas essenciais e prioritárias, o segundo oferece a força que pode desencadear, sustentar e reforçar a mudança.

\subsection{A base colaborativa}

Apesar de operar, frequentemente, em contextos de coacção e de servir, prioritariamente, clientes involuntários, o MAIFI constitui uma abordagem colaborativa. Uma postura colaborativa traduz-se, entre outros aspectos, no facto de os profissionais assumirem a família como parceiro pleno no processo de avaliação e de suporte para a mudança, de respeitarem e honrarem as suas experiências, competências e saberes. Num trabalho colaborativo, o 
profissional assume-se como especialista na condução dos diálogos e criação de condições de reflexão facilitadoras da mudança, ou seja, no processo da mudança mas não no conteúdo da mesma. O profissional assume que a direcção da mudança é imprevisível e incontrolável e que é determinada pela estrutura da família e ligação com o seu meio pelo que deve focar-se e trabalhar com ela para que sejam efectuadas propostas congruentes com aquelas. Os profissionais do MAIFI procuram ter uma actuação colaborativa: a) mantendo uma atitude de respeito para com a família e mostrando honrar as suas experiências e saberes; b) valorizando um registo reflexivo nos encontros com a família; c) procurando trabalhar a partir daquilo que a família já faz e das suas competências; d) ajudando a família a definir o rumo do processo e a definir as suas visões e direcções preferidas de vida; e) criando condições para a estimulação das competências da família e sua mobilização e ampliação; f) criando condições para que a família possa experimentar alternativas ao seu funcionamento, respeitando a sua autonomia e saber; g) separando a família dos problemas e ajudando-a a explorar e alterar a sua relação com os mesmos; h) deixando-se informar pela família sobre os melhores rumos de acção, respeitando as suas posições; j) mostrando querer saber e aprender com a família e fazendo uso de uma atitude de genuína curiosidade; k) agindo de forma transparente, clarificando intenções e partilhando responsabilidades com a família; I) negociando com a família os objectivos a alcançar e estratégias a adoptar. De forma congruente com a sua orientação colaborativa o MAIFI pressupõe que a mudança é melhor conseguida e, ao mesmo tempo, percebida, pela estimulação do exercício do direito à liberdade da família que é assim, entendido, simultaneamente, como um resultado desejado um contexto de mudança no MAIFI. Falamos da estimulação e desenvolvimento da flexibilidade e reflexividade da família de modo que possa aprender sobre os seus próprios mecanismos de mudança (aumentando a sua capacidade de adaptação e desenvolvimento positivo), sobre o mundo e a sua relação com o mesmo, e desenvolver a sua capacidade de experimentar e gerar alternativas ao seu funcionamento, fazendo escolhas autónomas, conscientes e responsáveis, congruentes com as suas preferências.

\subsection{A orientação para as forças e processos de resiliência}

O MAIFI assume que todas as famílias apresentam forças e recursos que podem ser recrutados para a mudança e que, muitas vezes, estão adormecidos ou bloqueados. Subscreve, ainda, a ideia de que todas as famílias têm o potencial para desenvolverem forças já existentes ou novas competências. Desta forma, o MAIFI inspira-se em modelos centrados nas forças para apoiar a família não só na fase de suporte para a mudança mas também 
durante a fase de avaliação a explorar, ampliar e desenvolver forças e recursos que a ajudem no processo de mudança e que a fortaleçam contra a adversidade futura. Nesse sentido, o MAIFI presta particular atenção à activação e ampliação de processos de funcionamento familiar que a literatura e investigação científica na área da resiliência individual e familiar afirmam poderem contribuir para uma melhor adaptação, e mesmo fortalecimento, não só dos indivíduos mas, também, das famílias, como um todo, a contextos de adversidade. Esta focalização é particularmente importante nos casos de múltiplos desafios e confere ao MAIFI um carácter não só remediativo mas, também, preventivo.

\subsection{0 foco nas soluções e a orientação narrativa}

Reconhecendo a seriedade e gravidade dos problemas que, frequentemente, afectam as famílias encaminhadas para o MAIFI, a abordagem aos mesmos é realizada, indirectamente, através de um enfoque nas soluções. Desta forma, os problemas são reconhecidos mas o trabalho com a família é foca-se em possíveis soluções, momentos de excepção ao problema e de competência família e a resultados desejados do que em estratégias de resolução de problemas. Neste processo, é atribuído um lugar de destaque ao papel da linguagem e à narrativa como elementos sustentadores da realidade e, por conseguinte, da mudança. Neste sentido, os profissionais do MAIFI dedicam um cuidado especial ao modo como falam com a família e sobre a família assumindo que nesses diálogos podem contribuir para transformar a realidade da família e o modo como os diferentes sistemas que com ela se relacionam a podem sustentar.

\section{COMO SE ARTICULA O MAIFI COM OUTROS SERVIÇOS E RESPOSTAS?}

O MAIFI é um modelo que visa complementar o trabalho de serviços já existentes na comunidade e, desejavelmente, proporcionar um tipo de apoio à família que muitos serviços sentem dificuldades em oferecer, seja por escassez de recursos humanos (ou despreparação dos mesmos) seja financeiros/materiais. O trabalho no MAIFI pretende-se temporário e deverá perseguir o objectivo de melhorar a qualidade da relação entre a família e os serviços com os quais a família poderá necessitar de continuar a manter contacto de um modo que permita um cumprimento eficaz dos objectivos desta relação, a preservação ou mesmo reforço de um sentido de autoria e agência da família, bem como de seu fortalecimento, com autonomia.

Uma vez que o MAIFI assume objectivos terapêuticos é fundamental garantir, aquando do encaminhamento, que a família não usufrui, em simultâneo, de outros serviços que visem a 
mudança familiar ou outro tipo de respostas terapêuticas com objectivos similares. Por outro lado, e para se evitar a diluição da família é de relevo que as diferentes vertentes de um projecto de apoio sejam integradas de modo a que a família possa manter o controlo do processo. Espera-se, ainda, que os diferentes projectos de apoio sejam articulados de forma a optimizar os recursos disponíveis e as forças familiares, evitando dispersão de esforços, e garantindo que as mudanças respeitam as visões e as direç̧ões preferidas de vida da família.

Uma vez que as famílias multidesafiadas têm que lidar com vários desafios e frequentemente em diferentes dimensões do seu funcionamento, uma resposta integradora, como é o caso do MAIFI, pode facilitar a sua adaptação e desenvolvimento positivo. O MAIFI pode, assim, articular diferentes intervenções, sejam aquelas prestadas pelos seus profissionais, sejam aquelas disponibilizadas por outros serviços, mediando a relação da família com os mesmos e, deste modo, minimizando os riscos da múltipla assistência.

Neste sentido, a equipa do MAIFI pode ser percebida como uma presença transitória na vida das famílias, na medida que o acompanhamento é orientado por objectivos bem definidos que, quando alcançados, deverão conduzir ao término do processo. Não obstante, a família pode usufruir, posteriormente, de outros serviços que a instituição onde o MAIFI é implementado, ou a sua equipa, possa, disponibilizar².

A equipa do MAIFI assume-se, deste modo, uma presença temporária na vida das famílias. No entanto, outras formas de cooperação com a família poderão ser desenhadas no âmbito de outros eixos de intervenção dos serviços que a integram, por exemplo ao nível do seu envolvimento no serviço de voluntariado, no centro de recursos ou ao nível das intervenções com a comunidade (Melo \& Alarcão, 2009).

A possibilidade de o processo de avaliação ${ }^{3}$ e da intervenção de suporte para a mudança serem geridos prioritariamente, pela equipa do MAIFI, pode contribuir minimizar a necessidade de multiplicação de contactos da família com os serviços e os riscos daí decorrentes. O trabalho no MAIFI deve ser percebido, contudo, como um trabalho de transição ${ }^{4}$, que termina quando os objetivos são cumpridos.

A natureza da relação e dos contactos entre a família, a equipa do MAIFI, o encaminhador e outros profissionais e serviços deve ser negociada, preferencialmente, na fase de

${ }^{2}$ Confrontar Melo \& Alarcão, 2009.

${ }^{3}$ Referimo-nos a avaliações de nível 4 segundo a proposta de Melo \& Alarcão, 2011

${ }^{4} \mathrm{O}$ processo de acompanhamento no MAIFI é orientado por objetivos bem definidos que, quando alcançados, deverão conduzir ao término do processo. A equipa assume-se, deste modo, uma presença temporária na vida das famílias. No entanto, outras formas de cooperação com a família poderão ser desenhadas no âmbito de outros eixos de intervenção do serviço onde a equipa se integra. No caso dos CAFAP, consideramos que por exemplo ao nível do seu envolvimento no serviço de voluntariado, no centro de recursos ou ao nível das intervenções com a comunidade (Melo \& Alarcão, 2009). 
encaminhamento. Algumas famílias necessitam de apoio prolongado em áreas específicas em função de necessidades particulares de alguns dos seus elementos ou da família com um todo e a maioria das famílias necessita, nalgum momento de recorrer a serviços de carácter universal (e.g. serviços de saúde). A articulação necessária e adequada entre os profissionais que apoiam a família deve ser definida e negociada no início do processo entre todos os envolvidos. Se é importante que a família, como sistema autónomo, possa continuar a assumir o controlo da gestão não só da sua vida diária e das necessidades associadas mas, também, do rumo desejado a longo prazo, então é importante que a família possa tratar daquilo que a ela Ihe diz respeito e possa lidar diretamente com os profissionais com os quais tiver que contactar. Contudo, se o contacto com os serviços ou a natureza destes serviços estiver relacionada, de forma especial, com a proteção da criança e o processo de promoção e proteção ou se relacionarem com as dificuldades que motivam o encaminhamento para o MAIFI então a equipa poderá propor ao encaminhador negociar-se com os profissionais envolvidos como estes contactos devem processar-se. Nestas circunstâncias, para evitar os riscos da multiassistência e que a relação com os serviços coloque dificuldades adicionais à família, a equipa pode propor-se assumir um papel mediador. Quer isto dizer que o contacto da família com outros profissionais, orientado para a formulação de um pedido ou obtenção de um serviço particular, deve ser primeiramente discutido com a equipa do MAIFI que passa a assumir funções de gestor de serviços, em estreita articulação com o encaminhador quando adequado. Isto é particularmente relevante quando existe o risco de duplicação de serviços ou prestação de serviços contraditórios ou que se anulem em termos de benefícios. Pode, ainda, ser especialmente útil quando a família apresenta dificuldades em efetuar pedidos adequados tendo em conta a natureza dos serviços, quando se apresenta perante os mesmos de forma desempoderada colocando em risco a sua autonomia ou quando ou quando tem dificuldade em cooperar com os serviços de acordo com normas mínimas socialmente estipuladas, colocando-se, assim, em risco de não ver as suas necessidades satisfeitas. Noutras situações esta função de mediação pode não ser necessária mas, quando se percebem dificuldades ora na relação da família com os serviços ora na condução do trabalho particular que lhes compete, a equipa do MAIFI pode oferecer-se para apoiar os intervenientes no estabelecimento de relações de trabalho mais positivas e na otimização do mesmo.

Nos casos em que a família esteja a receber serviços de natureza clínica, pode ser necessário avaliar em que medida eles são compatíveis com os objetivos do MAIFI. Na realidade, nalgumas situações o trabalho do MAIFI não deverá decorrer em simultâneo com outras respostas, principalmente se estas forem organizadas de acordo com princípios e orientações contrárias às do MAIFI. Nestes casos a acumulação de intervenções poderia ter 
consequências negativas para a família. O mesmo pode acontecer com serviços de carácter educativo que, visando a mudança familiar, assentem ora numa lógica de trabalho ora em leituras de compreensão do caso incompatíveis com as propostas no MAIFI. Nestas situações o encaminhador deverá abordar os profissionais envolvidos e, considerando pertinente 0 encaminhamento para o MAIFI, deverá negociar a suspensão das intervenções em questão enquanto o trabalho do MAIFI decorre. Noutras situações, considerando-se não existir incompatibilidade entre intervenções e podendo estas serem complementares os profissionais devem, ainda assim, articular-se de modo a garantir a manutenção destes benefícios e definir limites para cada intervenção. Todo este processo deve ser gerido pelo encaminhador em ligação com a família (secção 2, figura 2). Consideramos que na maioria das situações a família deve estar presente nas audiências com estes outros profissionais, abrindo-se exceções para as situações em que isso possa colocar em perigo a criança ou contribuir para um agravamento dos problemas apresentados.

A figura 1 apresenta um esquema da configuração ideal da relação entre serviços e família desde a fase prévia ao encaminhamento até ao término do processo. $O$ encaminhador pode optar por não reunir todos os profissionais mas deve informá-los da sua intenção de encaminhar a família para o MAIFI, auscultar o seu parecer e avaliar a sua disponibilidade para, posteriormente, participarem em reuniões de rede de profissionais orientadas para a definição de papéis e da relação entre os profissionais, a família e a equipa do MAIFI. Nas situações de proteção da criança, quando, ao longo do processo, houver necessidade de estabelecer contactos com as diferentes instituições e profissionais envolvidos com a família, tendo em vista a monitorização e controlo de indicadores de segurança e bem-estar da criança, deverá ser o encaminhador a assumi-los. Antes do encaminhamento, conforme ilustrado na primeira secção da figura 1, a família pode manter relações com diferentes serviços, relações, estas, que podem ser de naturezas muito diversas. Por seu lado, os serviços podem apresentar diferentes graus de articulação relativamente aos serviços prestados à família. Cabe ao encaminhador articular-se com todos os envolvidos para os convidar a apresentarem a sua posição sobre o encaminhamento para o MAIFI e apresentarem a sua disponibilidade para articularem ou reequacionarem o seu papel no contexto da avaliação conduzida pelo MAIFI e de um novo projeto de apoio à mesma que poderá surgir posteriormente à avaliação (secção 2, figura 1). 


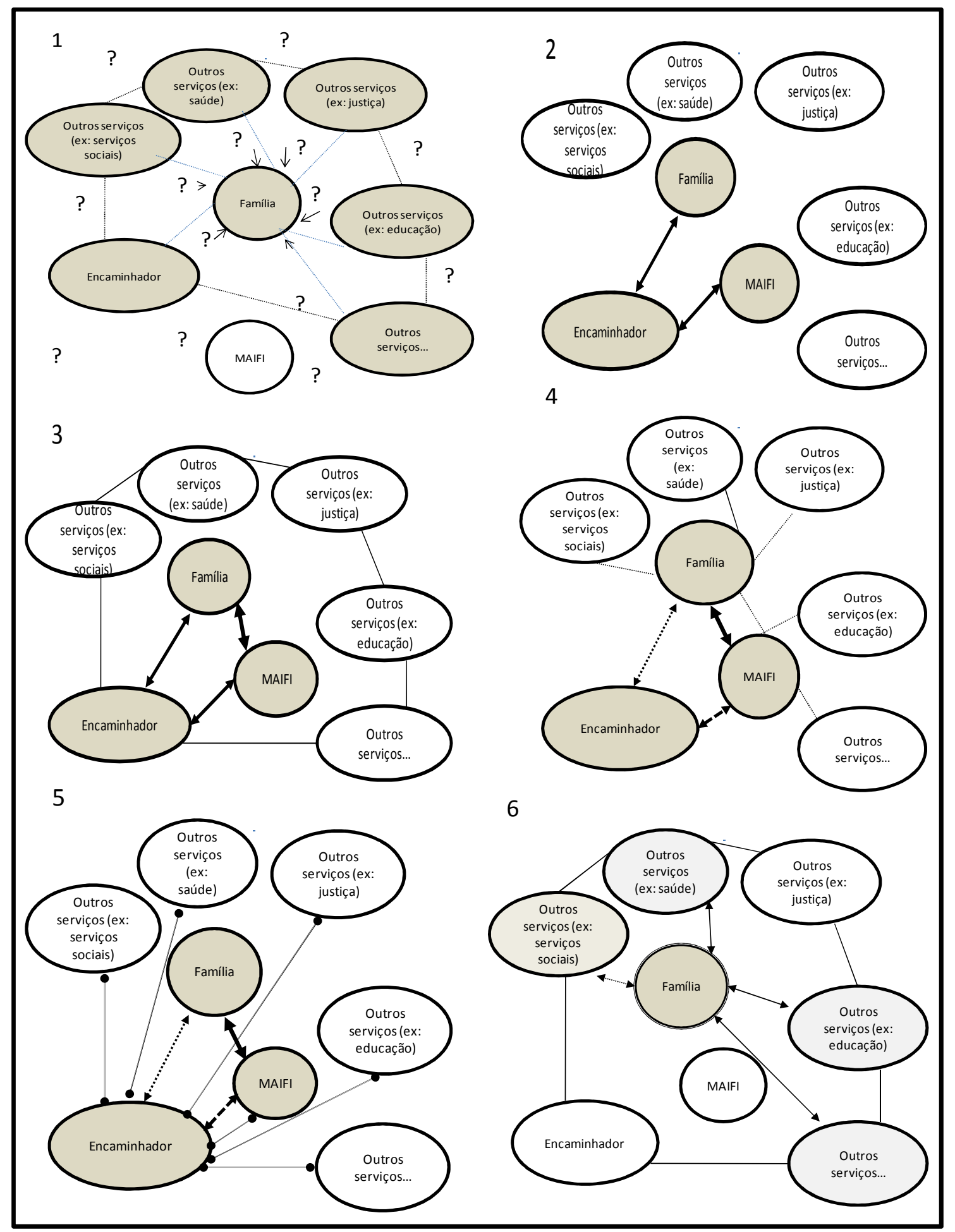

Figura 1- Configuração da relação da família, encaminhador, equipa do MAIFI e outros serviços, antes, durante, e após o encaminhamento para o MAIFI

No momento do encaminhamento (seç̧ão 3 da figura 1), o encaminhador assume uma relação privilegiada com a família, estabelecendo a ligação entre esta e a equipa do MAIFI numa configuração triangular que se espera equilibrada e funcional. O posicionamento dos outros serviços perante o encaminhamento pode ser muito diverso, mas deve ser discutido 
com a equipa do MAIFI e com a família. Desejavelmente, e no caso de não ter ocorrido nenhuma reunião prévia entre os profissionais envolvidos todos foram envolvidos e informados da decisão do encaminhamento e concordam com os seus objetivos. Quando adequado, o MAIFI passa a assumir uma posição de mediador do relacionamento com a família com as restantes instituições, que deixam de assumir a gestão do processo de apoio à família. Algumas relações passarão, eventualmente a ser mediadas pela equipa do MAIFI, ou a sofrer alterações no tipo de serviços prestados (e.g. com serviços sociais de justiça e determinados serviços educativos), outras manter-se-ão como habitualmente (e.g. escola, médico) e, noutras ainda, poderão ter a participação e apoio pontual da equipa do MAIFI (e.g. escola, médico) (secção 4, figura 1). O encaminhador continua a desempenhar um papel importante na estabilização do triângulo MAIFI-família-encaminhador na medida em que representa os resultados que têm que ser alcançados tendo em vista a promoção da segurança e bem-estar da criança. As funções de controlo e monitorização devem ser assumidas pelo encaminhador (secção 5, figura 1) que, contribui, assim para o sucesso do trabalho do MAIFI na medida em que permite à equipa manter presente a pressão necessária para que a mudança possa acontecer e ajudar a família a reafirmar o seu compromisso com a segurança e bem-estar da criança, sem ter que abdicar da sua função de suporte à família. É ao encaminhador que a família e a equipa do MAIFI terão que reportar os resultados do seu trabalho e é a este que cabem as decisões relevantes nos casos de proteção da criança. Após o término do acompanhamento no âmbito do MAIFI (secção 6, figura 1), a relação entre a família, a equipa e a entidade encaminhadora dilui-se e a família passa a relacionar-se diretamente com os serviços de que necessita, esperando-se que o faça de forma competente, preservando a sua autonomia e mantendo presente os seus rumos preferidos. Espera-se que a família conheça os serviços e recursos à disposição na comunidade e que possa recorrer aos mesmos sempre que necessário.Espera-se também que, nesta fase, as instituições que estavam envolvidas com a família, devido aos problemas apresentados aquando do encaminhamento, deixem de encontrar motivos que justifiquem a sua relação (pelo menos aqueles que eram motivo de preocupação inicial), passando a família a usufruir apenas dos apoios mínimos necessários para melhor gerir eventuais desafios que persistam relacionados, por exemplo, com a sua condição económica ou necessidades particulares de algum dos seus elementos. 


\section{INDICAÇÕES E CONTRA-INDICAÇÕES PARA O MAIFI?}

Não havendo propriamente muitas situações absolutamente contra-indicadas para o MAIFI haverá situações pouco indicadas e situações que exigem um trabalho prévio ao encaminhamento.

O MAIFI está particularmente indicado para situações de múltiplos desafios e/ou de maltrato e negligência. O processo de avaliação no MAIFI, sendo relativamente complexo, foi desenhado para poder ir ao encontro das necessidades, também elas complexas, da maioria destas famílias. Em situações excepcionais, outras circunstâncias de perigo para a criança ou jovem podem ser contempladas, caso se tratem de situações de múltiplos desafios.

As situações de problemas focalizados ou casos em que as dificuldades das famílias possam ser correctamente respondidas com respostas direccionadas para as mesmas, num número reduzido (ex: que não ultrapasse dois serviços/respostas distintas) poderão não ser situações particularmente indicadas para MAIFI. As situações de problemas focalizados que tenham implicado múltiplos desafios no passado podem, eventualmente ser indicadas, dependendo dos factores a que as dificuldades actuais estão associadas ${ }^{5}$.

Por outro lado, todas as situações em que as crianças, ou mesmo outros elementos da família, se encontrem numa situação de perigo iminente ou em que a sua segurança e integridade imediata esteja ameaçada, directa ou indirectamente (ex: proximidade com o perpetrador; ideação suicida de algum prestador de cuidados ou da própria criança; psicopatologia descompensada severa, particularmente do foro psicótico, ou abuso de álcool ou drogas graves com incapacitação parental; violência conjugal, etc.), devem ser devidamente avaliadas e, numa primeira instância, ser alvo de intervenções de crise e/ou de segurança (ex: aplicação de medidas de acolhimento; internamento de prestador de cuidados; planos de prevenção do suicídio; elaboração de planos de segurança por via de intervenções de rede, etc.).

Algumas situações como as acima exemplificadas não são indicadas para avaliação ou intervenção familiar se não houver um compromisso sério da família com a segurança e bemestar de todos os seus elementos, particularmente aqueles numa posição mais vulnerável. Assim, deve haver um trabalho prévio ao encaminhamento para o MAIFI que garanta a segurança dos elementos da família e a definição de um compromisso claro, passível de ser avaliado, dos adultos da família com a segurança e bem-estar dos elementos da mesma, inclusivamente durante a etapa de avaliação no MAIFI. Esta não poderá, pois, em momento

\footnotetext{
${ }^{5}$ Se as dificuldades actuais, ainda que aparentemente focalizadas, estiverem associadas à exposição a múltiplos riscos no passado e desafios que não foram completamente cumpridos, então a situação poderá ser indicada para o MAIFI.
} 
algum, colocar em perigo os elementos da família. Por conseguinte, algumas situações podem não ser indicadas para uma avaliação com enfoque familiar.

Casos com problemáticas específicas serão indicados apenas se os profissionais da equipa considerarem possuir preparação e qualificação suficientes para lidar com os mesmos (ex: situações de deficiências físicas ou mentais da criança).

Em caso de dúvida sobre a indicação/contra-indicação de uma situação para o MAIFI o encaminhador deverá consultar a equipa.

\section{QUE CONDIÇÕES DEVEM ESTAR ASSEGURADAS AQUANDO DO ENCAMINHAMENTO PARA O MAIFI?}

Há um conjunto de cuidados que é importante que o encaminhador adopte para que o encaminhamento para o MAIFI seja bem sucedido:

a) Deve haver avaliação da indicação do tipo de caso/ adequação ao MAIFI;

b) Nos casos de protecção, os factos que justificam a preocupação dos profissionais/sistema de promoção e protecção, devem ser claros e estar devidamente fundamentados;

c) Deve haver lugar a uma avaliação da segurança imediata ${ }^{6}$ da criança e ao desenvolvimento de planos de segurança, impliquem eles medidas de acolhimento (ex: acolhimento institucional; colocação com pessoa idónea, etc.) ou intervenções (ex: intervenções em rede) que garantam condições de segurança para a criança preservada no meio familiar?;

d) A família deve ter sido informada das características do trabalho da equipa do MAIFI e ter concordado com o encaminhamento;

e) Deve ter havido auscultação de outros profissionais a trabalhar com a família e concordância com o encaminhamento ${ }^{8}$ e com a gestão do caso por parte da equipa do MAIFI.

${ }^{6}$ Também entendida como avaliação do perigo imediato a que a criança está exposta.

${ }^{7}$ A este respeito, a equipa do MAIFI pode ser auscultada, antes do encaminhamento formal, na medida em que poderá apoiar o encaminhador na elaboração ou antecipação da elaboração de um plano de segurança. Este plano poderá ser negociado com a família aquando do encaminhamento e implicar, quando adequado, intervenção em rede e com a família para a preservação da criança na família, podendo a equipa colaborar não só na sua elaboração mas também na sua implementação e monitorização, se adequado.

${ }^{8}$ Caso o encaminhador considere pertinente, em situações excepcionais em que haja dúvidas entre os profissionais envolvidos no caso sobre a adequação do encaminhamento, a equipa do MAIFI poderá participar numa reunião de rede secundária tendo em vista a discussão da pertinência do encaminhamento e uma clara definição e articulação de papéis entre profissionais. 
O encaminhador poderá consultar o guião de preparação do encaminhamento para o MAIFI que procura apoiar os profissionais na estruturação do seu trabalho e na condução de avaliações e averiguações que antecedem o encaminhamento para o MAIFI.

\section{0 QUE PODE O ENCAMINHADOR ESPERAR DO MAIFI?}

Aquilo que o MAIFI pode oferecer ao profissional que encaminha uma família dependerá do tipo de caso e do seu enquadramento, nomeadamente do facto de se se tratar de um caso protecção ${ }^{9} \mathrm{com}$ ou sem múltiplos desafios enquadrado por um processo de promoção e proteç̧ão ou de um caso de risco psicossocial, associado a múltiplos desafios, mas sem existirem indicadores de perigo ou processo de promoção e protecção.

No caso de o encaminhamento ser feito no enquadramento de um processo de promoção e protecção, e de tratar-se, por conseguinte, de uma situação de perigo, o encaminhador pode esperar do MAIFI a devolução de informação, no contexto do encaminhamento para a avaliação, sob a forma de um relatório de avaliação que dê resposta a um conjunto pré-determinado de questões (ver ponto seguinte). Neste sentido, o encaminhador pode efectuar pedidos relacionados com a condução de avaliações que facilitem o processo de tomada de decisão, devendo as decisões a ser tomadas ser clarificadas aquando do encaminhamento. Por outro lado, poderá efectuar pedidos relacionados com o apoio à família tendo em vista o cumprimento de objectivos relacionados com a segurança e bem-estar da criança e solicitar informação relativa ao cumprimento dos mesmos.

Não obstante o pedido do encaminhador poder centrar-se no apoio para a mudança a equipa do MAIFI muito provavelmente proporá a condução de um processo de avaliação mais ou menos aprofundado dependendo das avaliações já realizadas. Esta avaliação, porque conduzida de modo colaborativo, deverá facilitar o envolvimento da família e a negociação de um projecto de suporte para a mudança com a mesma. Por outro lado, deverá identificar as dimensões e os processos sobre os quais o projecto de apoio deverá incidir para que a mudança possa ser facilitada e mais facilmente sustentada, congruente com as visões e direcções preferidas de vida da família, e para que possam ser activados processos que contribuam para o fortalecimento familiar e desenvolvimento positivo dos seus elementos. Assim sendo, a equipa enviará um primeiro relatório com os resultados da avaliação conduzida e relatórios posteriores informando do processo e resultado do projecto de suporte para a mudança.

\footnotetext{
${ }^{9}$ Particularmente situações de maltrato físico, psicológico e negligência
} 
Nos casos de risco psicossocial o encaminhador poderá esperar que os mesmos serviços sejam prestados mas, salvo algumas excepções, não verá devolvido relatório de avaliação, a não ser que isso seja pertinente para os objectivos do seu trabalho com a família, bem como para a própria e devidamente autorizado pela mesma. O conteúdo do relatório será discutido e acordado previamente, caso a caso, entre a família, o encaminhador e a equipa do MAIFI.

O encaminhador pode esperar do MAIFI a prestação de serviços flexíveis, desenhados à medida da família. Pode ainda esperar uma articulação clara no decorrer do processo, nos termos definidos aquando do encaminhamento.

O encaminhador não poderá esperar do MAIFI: a) a produção e disponibilização de informação que não tenham sido previamente acordadas; b) respostas absolutas às perguntas de avaliação ou aceitação de pedidos relacionados com a confirmação de avaliações anteriores ${ }^{10}$; c) a prestação de serviços de apoio focalizados em situações de múltiplos desafios sem a condução de uma avaliação compreensiva prévia; d) o trabalho de averiguação e substanciação do caso; e) a avaliação da segurança imediata da criança ou a responsabilização pela mesma fora do âmbito da elaboração de planos de segurança detalhados e devidamente fundamentados que, em caso de perigo elevado, envolvam vários intervenientes; f) a adopção de um papel de controlo ou monitorização de mudanças, em exclusivo, sem a colaboração de uma figura que assuma primariamente este papel; g) a garantia de prestação de todos os serviços que a avaliação indicar serem adequados para a família, caso a equipa não disponha de preparação adequada, entre outros aspectos particulares colocados por casos específicos.

\subsection{QUE PODE A FAMILIA ESPERAR DO MAIFI?}

A família pode esperar a disponibilização de serviços flexíveis em horas e espaços adequados às suas necessidades e constrangimentos das suas circunstâncias de vida. Pode esperar encontrar uma equipa disponível para atender às suas necessidades e, um apoio respeitador e empenhado para reflectir sobre os constrangimentos e potencialidades das suas circunstâncias actuais de vida e funcionamento, bem como a clarificar e perseguir as suas visões e direcções preferidas de vida, na medida em que sejam compatíveis com a segurança e bem-estar da criança. Pode contar com uma equipa que procurará conduzir a avaliação de uma forma justa, apoiando-a para que possa dar início às mudanças consideradas necessárias para que as crianças possam ser consideradas seguras e dispor de condições para um

\footnotetext{
${ }^{10}$ A equipa do MAIFI procurará, sempre, conduzir a avaliação de uma forma independente e isenta mantendo em aberto o maior número de possibilidades e resultados possíveis, o que significa que o resultado da avaliação pode nem sempre ir ao encontro das expectativas do encaminhador ou de outros profissionais.
} 
desenvolvimento positivo. A equipa do MAIFI pode comprometer-se com uma actuação transparente, com uma partilha aberta das preocupações e posições da equipa no decorrer do trabalho a desenvolver, para além de uma definição clara e negociada das condições de colaboração com a mesma e da relação com outros serviços. A família pode, ainda, esperar ser considerada parceira no processo de avaliação e ser convidada a partilhar as suas opiniões e visões, que serão tidas em consideração. A equipa compromete-se a apoiar a família, caso esta o deseje, na construção de condições favoráveis para o seu desenvolvimento e felicidade, para além dos objectivos estritamente relacionados com o estabelecimento de condições mínimas de segurança e bem-estar para a criança.

\section{QUAIS OS ASPECTOS PARTICULARES DA AVALIAÇÃO NO MAIFI?}

A avaliação no MAIFI caracteriza-se por integrar preocupações habitualmente presentes num processo de avaliação, com implicações forenses, em casos de protecção de maus tratos ou negligência (como seja o rigor na recolha e análise de informação, a utilização de múltiplos métodos, informantes, momentos e contextos de avaliação) com uma orientação colaborativa. Significa isto que a família é apoiada, desde o início, para que a mudança seja facilitada. Pelo enfoque não apenas no passado ou no presente, mas naquilo que a família pode ser capaz de fazer, pela valorização e ampliação das forças e recursos e centração nas soluções, a família vai sendo apoiada na reconstrução de diferentes dimensões da sua realidade que podem sustentar práticas cuidadoras das suas crianças e garantir a criação de condições de segurança e bem-estar para as mesmas. A condução da avaliação é guiada pela família e não apenas pelos padrões dos profissionais, sendo partilhada a responsabilidade do resultado. A avaliação no MAIFI procura ser sensível do ponto de vista cultural e criar oportunidades de acção e reflexão a partir das quais a família possa, mais facilmente, transformar a sua realidade. A fase de avaliação pode, assim, facilitar o envolvimento da família na fase de suporte para a mudança e transformar o momento de crise, muitas vezes associado à abertura de um processo de promoção e protecção, em oportunidade.

A avaliação no MAIFI pode integrar diferentes tipos de metodologias combinando métodos de avaliação clínicos ou por consenso com métodos de carácter mais empírico ou atuarial.

14. QUE TIPO DE AVALIAÇÃO É CONDUZIDO NO MAIFI? 
A fase de avaliação no MAIFI pode integrar diferentes tipos de avaliação, assentes em diferentes metodologias, que são integradas tendo em vista o cumprimento dos objectivos desta etapa.

Habitualmente, nos casos de protecção, o MAIFI pode levar a cabo uma avaliação do risco de (re)emergência de perigo, particularmente de mau trato ou negligência, uma avaliação compreensiva e, estritamente relacionada com esta, uma avaliação do potencial de mudança. Nas situações de risco psicossocial, a primeira categoria de avaliação pode não ser pertinente. Cada tipo de avaliação procura dar resposta a um conjunto pré-determinado de questões produzindo, assim, informação que pode apoiar o processo de tomada de decisão. Diferentes tipos de decisões podem ter que ser consideradas para um determinado caso. Muito embora a escolha do tipo e das questões de avaliação dependam do caso pode definir-se um conjunto geral de questões a que cada categoria de avaliação deve procurar responder ${ }^{11}$.

A avaliação do risco (de (re)emergência de perigo) pode informar a tomada de decisão acerca da urgência da intervenção bem como da intensidade e necessidade de controlo/ monitorização durante e após a mesma. No MAIFI, este tipo de avaliação, conduzida a par da avaliação compreensiva, procura dar resposta a questões ${ }^{12}$ tais como:

- Qual a probabilidade de ocorrência ou re-ocorrência de mau trato ou de reaparecimento das circunstâncias de perigo no futuro?

- Qual a probabilidade de dano futuro para a criança? Qual o tipo de dano e provável gravidade do mesmo caso ocorra?

- Há necessidade de intervenção?

- Os factores associados à (re)ocorrência de mau trato ou de reaparecimento de outras circunstâncias de perigo no futuro são passíveis de serem alterados? É possível geri-los adequadamente de modo a manter o risco controlado? (relacionada com a avaliação compreensiva e do potencial de mudança)

- Qual a disponibilidade e capacidade da família para desenvolver acções que permitam gerir adequadamente os factores associados a uma maior probabilidade de ocorrência ou re-ocorrência de mau trato ou de outras circunstâncias de perigo? (relacionada com a avaliação do potencial de mudança)

"Para uma revisão de diferentes tipos de avaliação e das questões de avaliação correspondentes consultar Melo, A. T. \& Alarcão, M. (2011). Avaliações em situações de risco e perigo para as crianças: Um roteiro organizador. Análise Psicológica, XXIX, 451-466.

${ }^{12}$ É dado particular relevo às questões mais centradas na gestão do risco, como é o caso das últimas três, do que à previsão do risco. 
A avaliação compreensiva no MAIFI está largamente dependente da formulação teórica associada à leitura compreensiva de um caso e à formulação de hipóteses sobre os factores que ora contribuíram para o aparecimento e/ou manutenção dos problemas ora podem contribuir para a mudança e para os resultados desejados. Esta categoria engloba, no MAIFI, a avaliação de competências parentais, do funcionamento familiar e de outros factores que afectam a capacidade parental, a avaliação de factores ambientais e sociais e uma avaliação focada na criança. Os resultados deste tipo de avaliação podem contribuir não só para a definição das dimensões sobre as quais um projecto de intervenção deve focar-se mas, também, para que se tomem decisões acerca do modo como diferentes componentes deste projecto devem ser articuladas. De um modo geral, as seguintes questões podem ser respondidas no âmbito de uma avaliação compreensiva:

- Quais as principais as situações de perigo ou de risco psicossocial que estão a ser avaliadas a que a criança está exposta e quais os mecanismos de risco e protecção associados ao desenvolvimento da família?

- Que tipo de decisões têm que ser tomadas relativamente ao nível e natureza do risco/probabilidade de (re)emergência de maus tratos ou das circunstâncias de perigo identificadas? Que factores podem contribuir para diminuir a probabilidade e controlar o risco de (re)ocorrência de mau trato ou outras circunstâncias de perigo?

- Que dimensões estão implicadas no aparecimento e/ou manutenção dos problemas/na construção de condições para um desenvolvimento seguro e positivo para criança e para a família? Que variáveis podem diminuir ou aumentar esses resultados? Como interagem entre si os factores de risco e de protecção?

- Que objectivos são adequados para um plano de mudança? Quais os resultados mínimos a atingir para que a criança possa ser considerada segura/ para que se considere que se aumentam as probabilidades de desenvolvimento positivo futuro da criança?

- Que tipo de estratégias de intervenção podem ser implementadas tendo em conta as decisões a serem tomadas e os resultados a serem atingidos? Quais as opções disponíveis e quais as vantagens e desvantagens? Como devem ser combinadas ou integradas as estratégias num plano de intervenção?

A avaliação do potencial de mudança, por seu turno, também associada à avaliação compreensiva, deverá permitir decidir pela adequação de propor-se um projecto de apoio à família, bem como pelas características específicas das estratégias a adoptar, ou por outras 
alternativas que contribuam para a segurança e bem-estar da criança e/ou introduzam mecanismos de protecção. Esta avaliação procura responder a questões tais como:

- A família está disponível para mudar e apresenta capacidade para envolver-se num processo de mudança? Qual o potencial da família para operacionalizar as mudanças necessárias para garantir condições mínimas de segurança e bemestar para a criança?

- Está disponível um tipo de intervenção que possa apoiar a família no processo de mudança e/ou na obtenção e desenvolvimento de recursos necessários à mesma? Que tipo de intervenção é mais adequado? Em que medida a família está capaz de beneficiar dessa intervenção?

Em função do tipo de decisões com que o encaminhador tem que lidar poderá solicitar ao MAIFI diferentes tipos de avaliação. Por norma, e como afirmamos anteriormente, a equipa necessita de conduzir uma avaliação compreensiva e, associada, uma avaliação do potencial de mudança, mais ou menos aprofundada, de modo a poder melhor preparar e negociar um projecto de suporte para a mudança com a família que respeite os princípios orientadores do modelo, as preferências da família e alcançar os resultados desejados.

\section{O QUE CARACTERIZA A FASE DE SUPORTE PARA A MUDANÇA NO MAIFI?}

O carácter integrador do MAIFI é particularmente visível na fase de suporte para a Mudança no MAIFI, etapa em que diferentes tipos de estratégias e metodologias podem ser incorporadas na medida em que respeitem os princípios orientadores do modelo. A etapa de suporte para a mudança pode ser gerida na totalidade pela equipa do MAIFI ou podem ser envolvidos outros profissionais ou elementos significativos da rede primária da família ou da comunidade.

Os projectos são negociados com a família e são definidos objectivos específicos e indicadores de avaliação. Os objectivos negociados normalmente emergem de forma natural no decurso do processo de avaliação.

Uma perspectiva narrativa subjaz a todo o processo na medida em que se considera que as narrativas da família organizarão e suportarão, em última instância, as mudanças comportamentais, cognitivas e emocionais. Dessa forma, é dedicada uma particular atenção ao modo como a família constrói, integra e dá sentido às mudanças que vão acontecendo e como elas se organizam numa história coerente compatível com as suas visões e direcções preferidas de vida. O processo de suporte para a mudança assenta no apoio à família para que 
experimente alternativas de funcionamento e faça escolhas conscientes, bem como para que encontre apoio para manter as mudanças desejadas. Tende a centrar-se em duas grandes categorias de mudanças, por um lado, mudanças a nível funcional (por exemplo, em diferentes dimensões de capacidade parental) e, por outro, a nível estrutural (nas regras e padrões de funcionamento da família). As mudanças a nível funcional tendem a ser contratualizadas em compromissos de mudança escritos, enquanto as segundas tendem a ser mais focadas em sessões familiares integradoras.

Ao longo de todo o processo e independentemente do tipo de estratégias utilizadas, do número de áreas em que se considera serem necessárias mudanças ou dos elementos da família envolvidos, decorrem sessões integradoras regulares, normalmente com toda a família, que visam ajudá-la a ampliar e recrutar as competências e forças aplicadas ou desenvolvidas numa determinada área para facilitar outras mudanças. Estas sessões têm, também, como objectivo ajudar a família a criar narrativas familiares mais facilitadoras do seu desenvolvimento e a expandir as suas capacidades de reflexão e mudança, procurando-se, ainda, activar e fortalecer processos associados à resiliência familiar.

\section{ETAPAS DO PROCESSO DE ENCAMINHAMENTO}

Descrevemos de seguida, e de forma resumida, o processo de encaminhamento para o MAIFI, listando um conjunto de tarefas que consideramos poderem ajudar a organizar o processo e contribuir para o seu sucesso:

a) Avaliação da indicação do caso para MAIFI;

b) Contacto preliminar com a equipa do MAIFI (ex: contacto telefónico) para avaliação da adequação do encaminhamento e recolha da ficha de encaminhamento, quando aplicável;

c) Tarefa pré-encaminhamento centrada na segurança imediata da criança

d) Tarefa pré-encaminhamento centrada no pedido e seu enquadramento: organização da informação disponível e necessidades.

e) Contacto com a família para discussão e preparação do encaminhamento;

f) Tarefa pré-encaminhamento centrada na rede de profissionais: contacto com profissionais da rede secundária da família para avaliar concordância com encaminhamento e definição de papéis;

g) Preenchimento da ficha de encaminhamento (consultar) 
h) Envio da ficha e possível contacto subsequente com a equipa do MAIFI para discussão da ficha ou esclarecimento de eventuais dúvidas e definição dos passos seguintes (ex: definir quem contacta a família e informa da data do acolhimento) 